Auster, $\mathrm{n}^{\mathrm{o}}$ 22, e034, 2017. ISSN 2346-8890

Universidad Nacional de La Plata.

Facultad de Humanidades y Ciencias de la Educación

Centro de Estudios Latinos

\title{
La selección del mito en la definición de la memoria de Troya: Eneida II
}

En el presente trabajo nos proponemos indagar el tema de la destrucción de Troya, narrada en el libro II de la Eneida de Virgilio, siendo ésta la primera fuente completa sobre los eventos acerca de la caída de la ciudad ${ }^{1}$. Analizaremos la especificidad del tratamiento del tema desde la perspectiva de un poeta romano, quien, en la selección mítica, pone énfasis en los siguientes puntos para definir la perfidia griega y la entrada del caballo a la ciudad manifestando la valoración con la que conforma los acontecimientos de un pasado mítico que en el texto perpetúa la memoria: el perjurio de Sinón, el portento mal interpretado de Laocoonte y la voluntad de los hados. Consideramos estos tres mitemas ${ }^{2}$ como las claves en las que descansa la intencionalidad de perpetuar la memoria del pasado mítico, puesto que, ya desde una primera lectura, confrontando estas representaciones con las secuencias míticas tomadas en otras fuentes, notamos una clara diferencia que iremos esbozando oportunamente.

\section{Fuentes literarias sobre el caballo de madera}

El libro II de Eneida se plantea narrativamente como una escena retrospectiva de los acontecimientos de la destrucción de Troya. Es el único documento completo sobre la

1 Austin, R. G., P. Virgili Maronis. Aeneidos. Liber Secvndvs, Oxford, Oxford University P., 1964, x. 2 Lévi-Strauss (Antropología Estructural, Buenos Aires, Paidós, 1987) define "mitemas", desarrollando la estructura de los mitos, como las unidades constitutivas del mito. Según explica: "Como toda entidad lingüística, el mito está formado por unidades constitutivas; estas unidades constitutivas implican la presencia de aquellas que normalmente intervienen en la estructura de la lengua, a saber, los fonemas, morfemas y semantemas. Pero ellas tienen con estos últimos la relación que los semantemas guardan con los morfemas y que estos guardan con los fonemas. Cada forma difiere de la precedente por un grado más alto de complejidad. Por esta razón, a los elementos propios del mito (que son los más complejos de todos) los llamaremos: unidades constitutivas mayores o mitemas."

Cita sugerida: Bisignano, J. A. (2017). La selección del mito en la definición de la memoria de Toya: Eneida II. Auster, (22), e034. Recuperado de: http://doi.org/10.24215/23468890e34 
leyenda y sobre el caballo de madera, aunque existen fuentes anteriores en las que el tema es representado de manera dispersa.

Según informa Pausanias, Ilias Parva de Lesches documenta la leyenda de Troya, ${ }^{3} \mathrm{y}$ en su descripción de la Acrópolis de Atenas, menciona el legendario caballo. En su representación, a pesar del estilo neutral que lo caracteriza, deja traslucir una alusión a la ingenuidad de los troyanos, característica probablemente común en la representación hecha por los autores griegos:

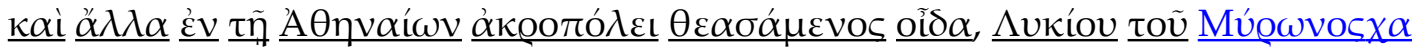
$\underline{\lambda \kappa O \tilde{U} v} \underline{\pi \alpha \tilde{\mathrm{i}} \alpha \alpha}[\ldots]$

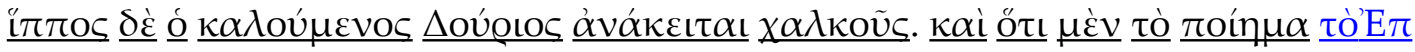

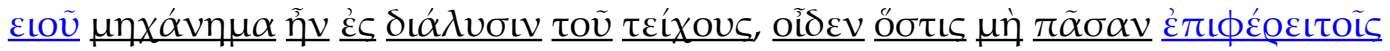

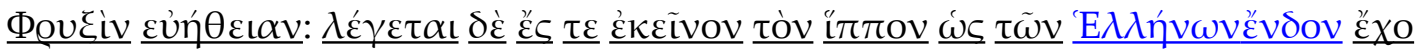

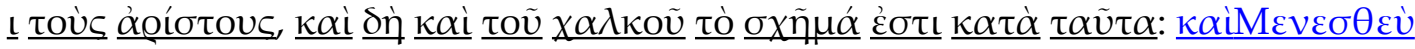

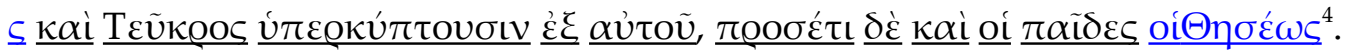

"Otras cosas que conseguí ver en la Acrópolis de Atenas: el niño de bronce de Licio hijo de Mirón [...] Está también el caballo de bronce llamado Durio (de madera); y quien no atribuye a los frigios una total ingenuidad, sabe que la obra de Epeo fue un artificio para abrir la muralla; pero se dice sobre aquel caballo que albergaba a los mejores de los griegos, y sin duda, la forma de este bronce es la misma de aquel; y Menesteo y Teucro se asoman desde él y además los hijos de Teseo." ${ }^{5}$

Se destaca al constructor, Epeo, que en Eneida permanece en el anonimato, y se pone énfasis en los hombres que había en su interior: "los mejores de los griegos [...] Menesteo y Teucro [...] los hijos de Teseo". Virgilio, por el contrario, presenta hombres sin nombre, son sombras oscuras y amenazantes esperando en su vientre. El acento está puesto en el terror, lo siniestro, la destrucción. Esta imagen de oscuridad contrasta asimismo con la representación homérica. En Odisea IV, 265 y ss., Menelao recuerda el episodio del caballo

3 Sobre el texto perdido Ilias Parva, Pausanias refiere "Macaón, según dice el autor del poema La pequeña Ilíada, fue muerto por Eurípilo, el hijo de Télefo". Díaz Tejera, A., Pausanias. Descripción de Grecia: Ática y Laconia, Biblioteca de Iniciación al Humanismo, Madrid, Aguilar, 1964, 266.

4 Spiro, F., Pausaniae Graeciae Descriptio, 3 vols. Leipzig, Teubner, 1903.

5 Díaz Tejera, Pausanias. Descripción de Grecia, 102. 
para referirse al sufrimiento que sintieron los griegos en el momento de la emboscada

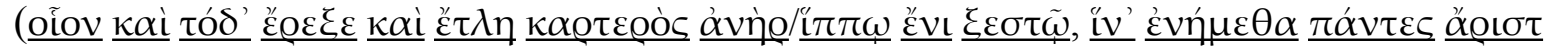
ot $^{6}, O d$. IV, 271-272 - “iqué no hizo y sufrió aquel fuerte varón en el caballo de pulimentada madera, cuyo interior ocupábamos los mejores argivos!"7); lo menciona también en el canto VIII, 492 y ss. aludiendo al suceso en forma imparcial, y en XI, 523 y ss. donde vuelve a mencionar los temores y nervios padecidos por ellos; la perspectiva es claramente distinta.

Mencionan también el caballo el Iliupersis de Arctino conocido a través de referencias en Proclo y en Pausanias, así como también el Iliupersis de Estesícoro; las tragedias griegas Hécuba (905 y ss.) y Troyanas (9-14 y 511 y ss.) de Eurípides, y Agamenón (823 y ss.) de Esquilo.

\section{El caballo de madera en Eneida II}

A partir de la narración en voz del troyano se le da una unidad a la historia de la destrucción puesto que ésta se centra en una sola persona, en lo que vio y experimentó. Desde su perspectiva se construye la historia del pasado mítico de Roma centrándose en el pathos, intentando obtener la empatía de su auditorio con el objeto, en un primer momento, de que le sean hospitalarios. Recordemos que Eneas había llegado a las costas frigias y este relato comienza a pedido de la reina Dido que desea informarse de su procedencia: Infandum, regina, iubes renovare dolorem, En., II. 3 (oh reina, me ordenas renovar un odioso dolor ${ }^{8}$ ). Destacamos aquí el adjetivo que utiliza para calificar los sucesos de la destrucción de Troya, el hecho es doloroso (dolorem) y a su vez es infandum. El término

6 Murray, A. T., Homer. The Odyssey, Cambridge, MA., Harvard University P.; London, William Heinemann, 1919.

7 Segalá y Estalella, L., Homero. Obras completas, Buenos Aires, El Ateneo, 1965.

8 Las traducciones del latín son propias. 
infandum quiere decir "que no se debe pronunciar, vergonzoso, abominable" en su acepción corriente, pero en su etimología está relacionado con la raíz de $\operatorname{fas}^{10}$ y es en el sentido en que está presente en estos versos del libro II, en los que resulta correcto interpretar que se trata de una injusticia divina que deberá tener su resarcimiento y lo tiene justamente en la construcción de la futura ciudad de Roma. La ciudad se yergue así envuelta en un hálito de justicia.

Creemos oportuno comentar en este sentido el análisis de Galinsky ${ }^{11}$ que considera Eneida como el aition (“el mito de origen") del pueblo romano, el establecimiento de un nuevo orden, incluyendo la ratificación de los cultos; pues ese pueblo se cimienta sobre las bases de una causa divina. Si bien los mitos etiológicos surgen de una larga tradición oral, Virgilio plasma en su obra una versión autorizada por el poder dominante en la que podemos observar las estrategias discursivas que definen la identidad romana en oposición a la alteridad griega. De este modo la secuencia mítica adquiere un grado de historicidad al vincularse con los ideales del pueblo romano.

La historia se presenta, desde el comienzo, de una manera trágica. Tal como lo señala Quinn ${ }^{12}$, la historia del libro II alcanza su clímax cuando Neoptólemo, el hijo de Aquiles, irrumpe en el palacio del rey Príamo acompañado de Agamenón y Menelao (En. II, 499-502).

9 "dont on ne doit pas parler, honteux, abominable [...] chose affreuse". Gaffiot, F. Dictionnaire LatinFrançaise. París, Hachette, 1951.

10 “Ses participes s'emploient avec le sens passif : fātus, d'où fatum, -ï (v. ce mot), fātārī attesté par Prise. III,

486, 12 et P. F. 78, 22, fatantur, multa fantur; fondus avec ses contraires infandus $(=\mathrm{a}) \dot{\mathrm{d}}$ lektoj, a) ¿rretoj, puis a)qe ¿mitoj) et nefandus (peut-être plus récent que infandus et influencé par nefas), cf. Catulle 64, 406, omnia fanda, nefanda malo permixta furore; d'où nefandārius (Not. Tir.). Cf. aussi nefāns, employé au pluriel neutre nefantia avec le sens de nefanda par Lucilius et Varron ap. Non. 489, 14 ; de même infäns facinus dans Accius". (Ernout, A. et Meillet, A., Dictionnaire Étymologique de la Langue Latine. Histoire des Mots, Paris, Éditions Klincksieck, 2001, 245).

11 Galinsky, K., "El drama griego y romano y La Eneida", Auster (8-9), 9-29.

12 Quinn, K. Virgil's Aeneid: A Critical Description, London and Ann Arbor, University of Michigan P., 1968. 
El narrador Eneas, en su discurso, asimismo, tiene como objetivo, no sólo destacar las virtudes de su pueblo en general, sino también configurar su propio personaje para caracterizarse finalmente como líder, manifestando expresamente que su huida de Troya está ordenada por los hados, pues él hubiera querido quedarse defendiendo la ciudad:

Iliaci cineres et flamma extrema meorum, testor, in occasu vestro nec tela nec ullas vitavisse vices Danaum, et, si fata fuissent ut caderem, meruisse manu................

$$
\text { II. } 431-434
$$

oh cenizas de Ilión, oh postreras llamas de los míos, sedme testigos de que en vuestra caída no esquivé ni los dardos de los griegos ni ninguno de los trances de la guerra, y, si los hados hubieran designado que yo cayera, lo habría merecido.

Quinn observa que el libro II contiene tres principales funciones estructurales: en primer lugar, tiene como objetivo relatar el pasado, tanto éste como el libro III narran eventos anteriores a modo de historia enmarcada. En segundo lugar, para generar la empatía del lector por Eneas. Puesto que en el libro IV su figura no generará simpatía, resulta necesario lograr la benevolencia del lector antes ${ }^{13}$; asimismo, el hincapié puesto en la misión que está llevando a cabo el héroe prepara el terreno para comprender su postura que perjudica a la reina Dido. Y en tercer lugar, a pesar de que por un lado Eneas obtiene la simpatía del lector, en el libro II se describe una serie de ilustraciones de la debilidad humana: su inadecuación a la tarea a la que está destinado, antes de que pueda ser el verdadero líder de su pueblo, tendrá que aprender, como veremos de nuevo en los libros IV y V, el control de sí mismo ${ }^{14}$.

13 Igualmente Gransden (Gransden, K. W., "The Fall of Troy", G\&R 32, 1985, 61) explica que Virgilio, detrás de la voz del héroe-narrador, presenta el libro como un paradigma estructural del libro IV.

14 Quinn, Virgil's Aeneid, 114. 
Es interesante notar, siguiendo a Austin ${ }^{15}$, que las escenas de este libro son similares en tamaño y estructura al episodio de Aristeo del libro IV de Geórgicas, y forman parte de un patrón de temas entrelazados, cuidadosamente proporcionados. Creemos que, si bien es un tema a estudiar en un trabajo aparte y merece un desarrollo en profundidad, una de las razones de este paralelismo consiste en la actitud de los personajes al intentar una alternativa a lo establecido por los hados. Un indicio de esto lo sugiere el sustantivo que utiliza Virgilio para referirse a la causa de la perdición de los troyanos y de Orfeo respectivamente: furor. En Geórgica IV, Orfeo baja al Averno a rescatar a Eurídice de la muerte pero no lo logra porque su furor no le permite acatar la regla que le imponen los $D i$ inferi; en Eneida II, los troyanos caeci furore (II, 244) no advierten las señales que indican la no recomendación de la entrada del caballo a la ciudad. Ambos sucesos narran un fracaso mortal.

Este episodio condensa cuál es el origen de Roma, y uno de los ejes centrales es la definición del romano en oposición al griego y su perfidia. Esta es la imagen que el gobierno de Augusto intenta proporcionar. La selección mítica de la descripción de la entrada del caballo a la ciudad confluye a forjar la imagen para la memoria de Troya y de los orígenes de Roma. La estampa de Eneas, Anquises y Iulo, seguidos de Creusa representa el esquema social y religioso, que son sinónimos para los romanos, en el que se apoya el Principado, que busca la validación de su derecho al poder en la gens escogida por los dioses y el destino, que es la de Augusto y reivindica el modelo de la sucesión genealógica, la supremacía masculina y un conjunto de valores parentales asentados en la religiosidad o $\operatorname{pietas}^{16}$.

15 Austin, R. G., "Virgil and the Wooden Horse", JRS 49, 1959, 16: "First the Horse appears; then Laocoon gives his warning, Sinon tells his tale, Laocoon and his sons perish; the Horse is taken into Troy, and its menace is fulfilled. The last name in the list of Greeks who come swarming out of it is that of its builder, and the pattern is finished."

16 Galán, L. Virgilio. Eneida. Una introducción crítica, Buenos Aires, Santiago Arcos Editor, 2005, 34. 
El objetivo de la épica romana, como está presente en los estudios de Grimal ${ }^{17}$, Galinsky $^{18}$ y Galán ${ }^{19}$, es expresar el período de Augusto, quien necesitaba un poema que viniera a justificar la fundación de una dinastía que él mismo estaba continuando. Augusto, como parte de su proyecto político, construyó un orden simbólico sustentado en el poder de las imágenes y verificado en el arte, los monumentos, el culto y los gestos semántica y simbólicamente fuertes.

Vemos graficado aquí de qué manera en Eneida se propone perpetuar una ideología que perdure como memoria y de qué manera entregar a la posteridad una imagen particular que defina la identidad romana. Podemos comprenderlo más apropiadamente si lo abordamos teniendo en cuenta el concepto teórico introducido por Williams de "tradición selectiva". Para éste, la tradición es la expresión más evidente de las presiones y límites dominantes y hegemónicos. Es el medio de incorporación práctico más poderoso. La tradición selectiva es "una versión intencionalmente selectiva de un pasado configurativo y de un presente preconfigurado, que resulta entonces poderosamente operativo dentro del proceso de definición e identificación cultural y social" ${ }^{20}$. Ciertos significados y prácticas son seleccionados y acentuados y otros son rechazados o excluidos, y esto es lo que ocurre en este recorte mítico enfocado a la definición de un origen, siempre con una intencionalidad subyacente. Williams explica que toda tradición constituye un aspecto de la organización social y cultural contemporánea del interés de la dominación de una clase específica. Es una versión del pasado que se pretende conectar con el presente y ratificar. En la práctica, lo que ofrece la tradición es un sentido de predispuesta continuidad. El establecimiento de una tradición selectiva depende en parte de instituciones identificables así como también de formaciones, con lo cual Williams ${ }^{21}$ entiende los movimientos y tendencias, en la vida intelectual y artística, que tienen una influencia sobre el desarrollo de

17 Grimal, P., El siglo de Augusto, Editorial Universitaria de Buenos Aires, 1965, 70.

18 Galinsky, "El drama griego y romano y La Eneida".

19 Galán, Virgilio. Eneida, 17.

20 Williams, R. Marxismo y Literatura, Buenos Aires, 2009, 137.

21 Williams, Marxismo y Literatura, 138. 
una cultura. Es en este sentido en el que Augusto logró la identificación de varios factores culturales con su proyecto político, entre ellos, Eneida.

Virgilio transfiere $\mathrm{y}$ transforma referencias de todo tipo $\mathrm{y}$ construye nuevas combinaciones de ellas al servicio de su visión poética y a su vez al servicio de la ideología de la clase dominante. Este método ha sido denominado la "integración virgiliana"22. En Eneida II, creemos que la selección mítica se estructura en torno a tres ejes:

\section{Perjurio de Sinón:}

Sobre las fuentes en torno al personaje de $\operatorname{Sinón}^{23}$ se conoce que los troyanos torturaron al griego en cuanto lo vieron. Virgilio toma todos los aspectos de las fuentes anteriores en las que aparece el personaje pero cuidadosamente no permite que los troyanos maltraten a Sinón, excepto mediante algunas burlas (undique visendi studio Troiana iuventus/ circumfusa ruit, certantque inludere capto, II. 63-64 - por todas partes la juventud troyana, con el afán de verlo, corre alrededor del cautivo y lo insulta-).

Clausen $^{24}$ sostiene que Virgilio omite la tortura de Sinón de parte de los troyanos porque es Eneas quien relata lo sucedido; en el texto no hay alusión alguna y el mensaje es bien claro: los troyanos no ofenden a los dioses.

En algunas versiones de la leyenda, Laocoonte es castigado por las serpientes porque, según lo interpretan los troyanos, ha maltratado anteriormente a Sinón. Esta parte, en correspondencia con la imagen benévola del pueblo de Troya, es excluida por Virgilio y tratada de otra manera: ya que este maltrato no existe, esta explicación no es posible en el texto y el único pérfido es el griego, contrastando con el respeto con que lo tratan los

22 Knight, W. F. J. Vergil's Troy. Essays on the Second Book of the Aeneid, Oxford, Basil Blackwell,1932, 74. 23 Quintus Smyrnaeus, The Fall of Troy, Way A. S. (trad.), London: William Heinemann; New York: G.P.

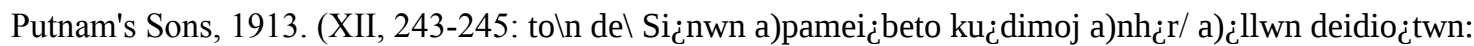

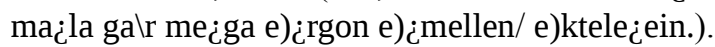

24 Clausen, W., Virgil's Aeneid. Decorum, Allusion and Ideology, München-Leipzig, Saur, 2002, 58-74. 
troyanos; ante el engañador griego, Príamo desde un primer momento se muestra gentil y amigo:

His lacrimis vital damus et miserescimus ultra. ipse viro primus manicas atque arte levari vincla iubet Piamos dictisque ita fatur amicis

\section{II. $145-147$}

Grandemente compadecidos de sus lágrimas, le concedemos la vida; el mismo Príamo manda el primero que le quiten las esposas y los apretados cordeles, y le dirige estas amistosas palabras.

Estas características destacadas en la contraposición de actitudes demuestran la intencionalidad de conformar la identidad cultural y social del romano, no sólo apartándose de la alteridad griega, sino acentuando el carácter piadoso y respetuoso de los troyanos representados con el objetivo de crear una "predispuesta continuidad" con la identidad romana contemporánea al poema.

Sinón, en su discurso, construye un cuadro de su propia pietas. Comienza apelando a la ley de la hospitalidad, actitud propia de hombre que cultiva la virtus, como primer recurso falaz para lograr la empatía de los troyanos; al presentarse como víctima de Ulises gana tanto credibilidad como simpatía de sus oyentes ${ }^{25}$ : Heu, quae nunc tellus, inquit, quae me aequora possunt/ accipere? Aut quid misero mihi denique restat, II. 69-70 (¡Oh! Exclama ¿Qué tierra, qué mares podrán recibirme ahora? ¿O qué me queda, finalmente, desdichado de mí?), y enseguida se define como un compatriota diciendo neque apud Danaos usquam locus ("ya no tengo ningún lugar entre los dánaos”, II. 71). Eneas, que recrea las palabras de Sinón mediante el discurso directo, interrumpe para contar a su auditorio que ante esa presentación que hace el griego, ellos cambian su actitud defensiva y se disponen a escuchar lo que tiene que decir; en otras palabras, le creen (quo genitu conversi animi, compressus et omnis/ impetus, II. 73-74 -“"nuestros ánimos se cambian por

25 Gransden, "The Fall of Troy", 64. 
su lamento y todo nuestro ímpetu se apacigua"). Siguen las palabras de Sinón prometiendo veracidad, fidelidad: cuncta equidem tibi, Rex, fuerit quodcumque, fatebor/ vera II. 77-78 ("te confesaré toda la verdad, rey, suceda lo que suceda"). Y luego de contarles su historia de enemistad con Ulises, una vez más se muestra en complicidad con la perspectiva troyana sobre el pueblo griego como engañador: si omnis uno ordine habetis Achivos, / idque audire sat est? II. 102-103 ("si tienen en un solo concepto a todos los aqueos ¿es suficiente lo que oyeron?"). Seguidamente cuenta que él ha huido antes de ser sacrificado para aplacar al dios Apolo y pide piedad:

Quod te per superos et conscia numina veri, per si qua est quae restet adhuc mortalibus usquam intemerata fides, oro, miserere laborum tantorum, miserere animi non digna ferentis

\section{141-144}

Por los dioses y por los númenes que conocen la verdad, Por la inmaculada fe si aún permanece alguna entre los mortales Te ruego, apiádate de tantas desventuras, Apiádate de mi espíritu que soporta cosas indignas.

Inmediatamente les explica que han construido el caballo para expiar el robo del Paladio ${ }^{26}$, como parte constitutiva de la religio. Lo conecta con una Minerva ofendida y los troyanos deben hacer su parte para no ofenderla ellos también ${ }^{27}$ :

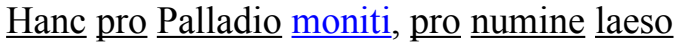
effigiem statuere, nefas quae triste piaret.

II. $183-184$

Advertidos, emplazaron esa estatua en lugar del Paladio, en lugar de la diosa ofendida, para expiar el horrible sacrilegio.

Ante este engaño del griego, los troyanos se apiadan, le creen, puesto que no pueden imaginarse semejante ficción que implica una herejía.

26 Para Austin ("Virgil and the Wooden Horse", 20), Virgilio omite hablar de toda la tradición sobre el robo del Paladio porque detenerse en la anécdota debilitaría el argumento de Sinón.

27 Austin, "Virgil and the Wooden Horse", 20. 
Virgilio construye una imagen de la etnia griega que se relaciona con la violación de la esfera sagrada ${ }^{28}$. En el discurso de Sinón se establecen varias faltas a la divinidad de parte de los griegos: afirmar que es una ofrenda sagrada; utilizar el lenguaje corporal del rito y las fórmulas establecidas para argumentar su falso discurso; poner de testigos a varias divinidades y objetos de culto al inviolable numen; resaltar otra ofensa sagrada como el robo del Paladio, que conlleva otras como la destrucción del templo, y acudir al léxico religioso para que al fin los troyanos introduzcan el caballo a la ciudad.

\section{Profecía de Laocoonte:}

La crítica $^{29}$ analiza los dos episodios (el engaño y la muerte de Laocoonte) interrelacionados.

Putnam $^{30}$ ve a Laocoonte como la primera víctima del sacrificio simbólico de la destrucción de la ciudad, y Knox ${ }^{31}$ lo entiende como una "profecía simbólica” de la caída de Troya como un todo. Al respecto observamos que así como varios elementos se trastocan en esta escena siniestra, el mismo sacerdote que está comenzando su sacrificio, es sacrificado (Laocoon, ductus Neptuno sorte sacerdos,/ sollemnis taurum ingentem mactabat ad aras, II. 201-202 - Laocoonte, designado por la suerte como sacerdote de Neptuno/ sacrificaba, solemne, un enorme toro ante los altares). Austin sostiene que este

28 Bogdan, G., La representación de la religio en Eneida de Virgilio. Tesis de posgrado. Universidad Nacional de La Plata. Facultad de Humanidades y Ciencias de la Educación. En Memoria Académica. Disponible en: http://www.memoria.fahce.unlp.edu.ar/tesis/te.1160/te.1160.pdf, 2015, 199 ss.; Ames, C. y de Santis, G. "La construcción de identidades étnicas en el estado augusteo. El ejemplo de la Eneida", Estudios clásicos 17, 2013, 1-24.

29 Manuwald, G. "Improvisi aderunt. Zur Sinon-Szene in Vergils Aeneis", Hermes 113, 1985, 115; Block, E., The Effects of Divine Manifestation on the Reader's Perspective in Vergil's Aeneid, Salem, N. H., Ayer Company, 1984, 54; Hardie, P., Virgil's Aeneid. Cosmos and Imperium, Oxford, Clarendon P., 1986, 56; Smith, R. A., The Primacy of Vision in Virgil's Aeneid, Austin, University of Texas P., 2005, 50; Putnam, M., The Poetry of the Aeneid: Four Studies in Imaginative Unity and Design, Cambridge, Mass., Harvard University P., 1965, 24.

30 Putnam, M., The Poetry of the Aeneid, 24.

31 Knox, B. M. W., "The Serpent and the Flame: The Imagery of the Second Book of the Aeneid", AJPh 71, $1950,382$. 
evento, no sólo inesperado sino disruptivo de la acción, provoca que una escena de solemne ritual religioso se torne un acto de terror ${ }^{32}$.

Sobre el portento de Laocoonte, Grimal ${ }^{33}$ ofrece una interpretación: la leyenda informa que, siendo sacerdote de Apolo, atrajo la cólera del dios, cuando se unió con su mujer Antíope ante la estatua consagrada, lo cual constituía un sacrilegio y debía ser expiado o castigado. Ante el prodigio de las serpientes, los troyanos lo relacionan directamente con que éste se había opuesto a que se introdujese en la ciudad el caballo abandonado por los griegos, había aconsejado quemarlo e incluso había disparado contra él una jabalina ${ }^{34}$. Creyeron que la muerte de Laocoonte era un castigo por este acto sacrílego, cuando en realidad, aunque ellos no podían saberlo, Apolo vengaba otro sacrilegio: la profanación de su templo.

Esta interpretación que hace Grimal sobre el castigo de Laocoonte es posible en la tradición mítica pero en Eneida Virgilio no toma este aspecto del mito ya que en su versión no se remite a su pasado, por lo tanto las lecturas posible del portento sería la que hicieron los troyanos o la contraria, que luego de conocer la sucesión de los hechos, sabemos que es la correcta: las dos serpientes representan a Agamenón y Menelao destruyendo a los troyanos o más genéricamente, a las tropas griegas sobre las troyanas ${ }^{35}$. El aviso profético no es correctamente interpretado. Al respecto, $\mathrm{Knox}^{36}$ analiza el episodio de las serpientes como una comparación de la naturaleza feroz y engañadora de los atacantes griegos, y de su arma principal, el fuego. Sostiene que la imagen es ambivalente puesto que además de sugerir las fuerzas de destrucción, también sugiere el renacimiento, la renovación que la

32 Austin, "Virgil and the Wooden Horse", 21.

33 Grimal, P., Diccionario de mitología griega y romana, Buenos Aires, Paidós, 2001, 304.

34 La lanza puede tratarse de una invención de Virgilio (Austin, "Virgil and the Wooden Horse", 18).

35 Knox analiza la relación, que se construye en clave metafórica en el texto, entre entrada del caballo a la ciudad y las serpientes. El caballo entra moviéndose como una serpiente. "The most striking correspondences are: gemini a Tenedo, of the serpents, a Tenedo, of the fleet (203 and 255); tranquilla per alta, of the serpents, tacitae per amica silentia lunae, of the fleet (203 and 255); pariter of the serpents, instructis navibus, of the fleet (205 and 254); ad litora tendunt, of the serpents, litora nota petens, of the fleet (205and 256). Knox, "The Serpent and the Flame", 387.

36 Knox, "The Serpent and the Flame", 380. 
tradición poética latina asoció con la desaparición de la vieja piel de la serpiente en primavera. Esta connotación de la serpiente es de suma importancia para el segundo libro de Eneida, ya que alude a la promesa de resurgimiento latente en la agonía de la destrucción, y, siguiendo esta línea de significaciones, en la imagen de la llama (En., II. 684 y ss.), que el lenguaje alusivo de Virgilio presenta como la manifestación final de la metáfora de la serpiente, se manifiesta el presagio del renacimiento de Troya.

Virgilio omite la falta de Laocoonte previa sobre Apolo, porque para la historia es irrelevante ${ }^{37}$ y además cuenta un acto de sacrilegio por parte del troyano que perjudicaría su caracterización. Como es Atenea y no Apolo la que manda las serpientes ${ }^{38}$, se entiende que Virgilio deja de lado en su totalidad la falta cometida anteriormente pues si quisiera dejar entrever una parte del mito que no explicita en su texto, hubiera representado al dios como el que produce el castigo ${ }^{39}$, y esta es otra razón por la que no toma el aspecto del mito del personaje sacrílego ya que Apolo debería presentarse como vengador y, en esta versión no interesa retomar esa característica del dios En la selección mítica se excluye este aspecto con la intención de presentar un dios apaciguador, propio del período de Augusto ya que el Princeps lo veneraba particularmente y el dios siempre actúa de parte de los troyanos como se plantea tradicionalmente desde Ilíada.

La figura de Laocoonte que ni siquiera es mencionada en Odisea, y lo es superficialmente en otras fuentes, en Eneida aparece como protagonista. Su autoridad para definir la entrada o no del caballo dentro de la fortaleza es decisiva puesto que los troyanos deciden aceptarlo a causa del portento. El personaje de Casandra, quien en otras versiones

37 Knight, Vergil's Troy, 89.

38 At gemini lapsu delubra ad summa dracones/ effugiunt saevaeque petunt Tritonidis arcem,/ sub pedibusque deae clipeique sub orbe teguntur, II. 225-227 - y las dos serpientes huyen deslizándose hacia el alto santuario, buscan el templo de la cruel tritónida, y se esconden bajo los pies de la diosa y del círculo de su escudo-.

39 Knight, Vergil’s Troy, 90. 
advierte sobre las consecuencias fatídicas, no tiene cabida en esta escena para no subordinar su actuación y hacerlo accionar independientemente de la profetisa ${ }^{40}$.

Finalmente creemos que el mitema pone de manifiesto lo siniestro de la situación, va preparando una escena oscura que refuerza la imagen de terror causada por el caballo.

\section{El hado}

En el libro II varios factores confluyen a acentuar y destacar la incidencia y presencia del hado; por un lado, a través de las divinidades: los dioses están enunciados en todo momento, en un principio Eneas lleva a sus Penates, como dioses compañeros y asistenciales, y este gesto reivindica un acto de religiosidad y respeto que marca una característica distintiva del troyano que continuará sin interrupción generación tras generación hasta los romanos.

Los dioses, además, están presentes como anunciadores del destino, ya sean benefactores de los troyanos como por ejemplo Venus, que se presenta para apaciguar a Eneas en el momento en que el héroe se encuentra dominado por la ira contra Helena y le augura un destino favorable: eripe, nate, fugam finemque impone labori./ nusquam abero et tutum patrio te limine sistam, II. 619-620 ("huye, pues, hijo mío, y pon fin a los trabajos. En dondequiera me tendrás a tu lado y te dejaré seguro en tus nativos umbrales"); ya sean hostiles como Júpiter que infunde aliento a los Dánaos y los favorece ${ }^{41}$. El "padre de los dioses" y los demás dioses adversarios ponen en relieve la idea de que lo sucedido está destinado a ocurrir.

40 Austin sostiene al respecto: "Virgil had his reasons for not introducing Cassandra at this point: a speech from her now could only have blunted the sharpness of the crisis-she was fated never to be believed, but Laocoon could be believed, and Virgil has used all his art to bring him as near winning belief as was humanly possible." (Austin, "Virgil and the Wooden Horse", 18).

41 Ipse pater Danais animos viresque secundas/ sufficit, ipse deos in Dardana suscitat arma, II. 617-618 (El mimo padre infunde ánimo y fuerzas favorables a los dánaos, él mismo empuja a los dioses contra las armas troyanas.) 
Por otro lado, el fatum es anunciado a través de los portentos que se dan de una manera continua en todo el libro: Troiae sic fata ferebant (II. 34, así lo tenían dispuesto los hados de Troya). Y se representan en varias oportunidades a través de los personajes como por ejemplo la aparición de Héctor a Eneas, para asegurarle su éxito luego de la destrucción de su pueblo:

sacra suosque tibi commendat Troia penatis; hos cape fatorum comites, his moenia quiere magna, pererrato statues quae denique ponto.

II. $293-295$

Troya te confía sus númenes y penates, toma contigo esos compañeros de sus futuros hados, y busca para ellos nuevas murallas, que fundarás, grandes por fin, después de andar errante mucho tiempo por los mares.

El fatum, como sabemos, está ya establecido, por lo tanto los troyanos están inermes ante él, no pueden revertir el curso de las cosas. Aunque se les anuncie la ruina, no son capaces de interpretar correctamente los avisos:

......................quater ipso in limine portae

substitit atque utero sonitum Quatre arma dedere; instamos tamen immemores caecique furore et monstruo infelix sacrata sistimus arce.

\section{II. $242-245$}

Cuatro veces se paró la enemiga máquina en el mismo umbral de la puerta y cuatro veces se oyó resonar en su vientre un crujido de armas. Avanzamos, no obstante, desatentados y ciegos en nuestro delirio, y colocamos el fatal monstruo en el sagrado alcázar.

Pareciera que ellos podrían haber evitado el desastre porque existieron advertencias en varias ocasiones y las hubieran sabido interpretar de no estar ciegos de locura. Eneas se lamenta desde el inicio de su relato de no haber podido advertir los anuncios (Et, si fata deum, si mens non laeva fuisset,/ impulerat ferro Argolicas foedare latebras,/ Troiaque, 
nunc stares, Priamique arx alta, maneres, II. 54-56 - "Y, si los hados de los dioses y nuestro ánimo no hubieran sido adversos, nos habría empujado a atacar los escondites argivos, y ahora estarías de pie, joh Troya!, y permanecerías, alta torre de Príamo”), pero el destino es inexorable y Virgilio, como justificación de esta verdad irrefutable, representa a sus personajes como presos del furor y de una mens laeva, immemores. Recordamos que en Geórgica IV con esas mismas palabras describe a Orfeo, immemor ( $G$. IV, 490). Preso del furor $(G$. IV, 494) no logró resucitar a Eurídice, sin embargo su demencia no fue la causa de su fracaso sino que en realidad no hay opción para que se produzca la resurrección porque Orfeo, como mortal, no puede tener jamás ese poder, los hados priman.

La selección mítica respecto del fatum, no solo reivindica el respeto romano religioso y la sumisión ante un poder superior, sino que esta concepción de la posibilidad de interpretación de sus señales, enraizada desde los orígenes de la estirpe, sustenta la creencia en la adivinación sostenida por Augusto, quien recurría a los portentos e incluso se presentó como el único capaz de interpretar lo profetizado por el dios Apolo. Esta creencia, que busca la autoridad en el pasado, refuerza claramente una institución política y social vigente en el principado: el sistema augural.

La función de este episodio, según Quinn ${ }^{42}$, es sugerir que la destrucción de Troya hecha por los dioses no es un acto de malevolencia sin propósito, sino la elaboración de un plan divino que es constructivo a su vez que destructivo: cae Troya y surge Roma. En realidad, los troyanos no caen sino que accionan acarreando la empresa fundadora cimentada en los pilares básicos de la identidad troyana que se pretende exhibir como fundida con la romana: la virtus, marcada por contraste con el pérfido griego y por el comportamiento honroso de Eneas y de los personajes troyanos desarrollados en este libro (ej: Príamo), la pietas, expresada en el encuentro de Eneas con Helena y el respeto y sometimiento a la tutela de los dioses.

42 Quinn, K. Virgil's Aeneid, 118. 
Todo el libro II, partiendo del tema mítico, se plantea como un capítulo de la historia verdadera del pueblo romano ${ }^{43}$. La versión de la identidad troyana - romana que se construye está en marcada oposición al griego y fundada en base a los conceptos de virtus, clementia, iustitia y pietas, está vinculada directamente con la representación del mos maiorum y el respeto de las tradiciones y coincide con la imagen que de sí mismo pretende construir el Princeps.

Julia A. Bisignano Universidad Nacional de La Plata juliabisig@gmail.com

\title{
Resumen:
}

Nos proponemos indagar el tema de la destrucción de Troya, narrada en el libro II de la Eneida de Virgilio, siendo ésta la primera fuente completa sobre los eventos acerca de la caída de la ciudad. Analizamos la especificidad del tratamiento del tema desde la perspectiva de un poeta romano, quien, en la selección mítica, pone énfasis en los siguientes puntos para definir la perfidia griega y la entrada del caballo a la ciudad manifestando la valoración con la que conforma los acontecimientos de un pasado mítico que en el texto perpetúa la memoria: el perjurio de Sinón, el portento mal interpretado de Laocoonte y la voluntad de los hados.

Palabras clave: Eneida II - Sinón - Laocoonte - hados

\begin{abstract}
:
We propose to examine the subject of the destruction of Troy, as it is told in Aeneid II. This is the first complete source about the fall of Troy. We analyze the specific treatment of the subject from the perspective of a Roman poet who, in his mythical selection, emphasizes the following elements of the Greek perfidy and the entering of the Horse to the city, showing the value of the events of a mythical past which in the text perpetuates the memory: Sinon's perjury, the portent misinterpreted by Laocoon and the will of the fate.
\end{abstract}

Keywords: Aeneid II - Sinon - Laocoon - fate

RECIBIDO: 4-7-2017 - ACEPTADO: 8-10-2017

43 Austin, "Virgil and the Wooden Horse", 24. 